\title{
Contextos
}

\section{Espacio y tiempo del taller de proyectos arquitectónicos: la Escuela de Arquitectura de Valencia}

Space and time of the design studio: the Architecture School of Valencia

\author{
Débora Domingo-Calabuig \\ Universitat Politècnica de València (España) \\ Escuela Técnica Superior de Arquitectura \\ Departamento de Proyectos Arquitectónicos
}

\section{Laura Lizondo-Sevilla}

Universitat Politècnica de València (España)

Escuela Técnica Superior de Arquitectura

Departamento de Proyectos Arquitectónicos

\author{
Débora Domingo-Calabuig \\ Arquitecta, Universitat Politècnica de València, España (UPV) (1997). Doctora arquitecta, UPV (2005). Profesora, \\ Departamento de Proyectos Arquitectónicos de la UPV desde 2000. Subdirectora de investigación, E. T. S. de \\ Arquitectura de la UPV (2012-2018). Editor in Chief de VLC arquitectura Research Journal (2014-2018). Inves- \\ tigación centrada en la arquitectura y el urbanismo de la posguerra europea; especialmente, en los cambios en \\ la educación superior y los nuevos campus. Publicaciones en: Architectural Review, EGA, Architectural Research \\ Quarterly, dearq, PPA, ZARCH y ArquiteturaRevista. \\ https://scholar.google.es/citations?user=EW6edscAAAA|\&hl=es \\ (D) https://orcid.org/0000-000I-6020-34I4 \\ (10) dedoca@pra.upv.es \\ Laura Lizondo-Sevilla \\ Arquitecta, Universitat Politècnica de València, España (UPV) (2003). Doctora arquitecta, UPV (20I2). Profesora, \\ Departamento de Proyectos Arquitectónicos de la UPV desde 2008. Visiting scholar en GSAPP, Columbia Univer- \\ sity, New York (20II). Visiting Researcher en Central Saint Martins, University of Arts of London (2015). Investi- \\ gación en el campo de la crítica arquitectónica del movimiento moderno y la arquitectura docente de la posguerra, \\ publicada en: EGA, ACE, ARQ, PPA, BAc, VLC Journal, JSAH, METU-JFA y ArquiteturaRevista. Directora, Cátedra \\ puanca Valencia. Editor in Chief de En Blanco. Revista de Arquitectura.
Blaticada \\ https://scholar.google.es/citations?hl=en\&pli= I \&user=e4sWikAAAAA \\ (1D) https://orcid.org/0000-0003-0376-0593 \\ (a) laulise@pra.upv.es
}

Domingo-Calabuig, D. y Lizondo-Sevilla, L. (2020). Espacio y tiempo del taller de proyectos arquitectónicos: la Escuela de Arquitectura de Valencia. Revista de Arquitectura (Bogotá) 22(2), 3-II. https://doi.org/10.14718/RevArq.2020.3389

\section{Resumen}

Tanto la teoría del proyecto arquitectónico (qué se enseña) como su metodología (cómo se enseña) cuentan con una notable tradición que se enriquece constantemente con nuevas perspectivas; sin embargo, cuando hay que diseñar el taller de proyectos, las concreciones pedagógicas se dan con los objetivos específicos de la formación (para qué se enseña) y con la disponibilidad de recursos (con qué se enseña). Este texto reflexiona sobre la temporalidad y la espacialidad del taller de proyectos arquitectónicos como factores determinantes a la hora de dar forma a una epistemología del proyecto. La hipótesis se evidencia mediante un caso de estudio: se analiza una unidad docente de la Escuela de Arquitectura de Valencia, que bien podría ser representativa de otras escuelas españolas. Los resultados demuestran cómo las actividades concretas que acompañan al estudiante en el taller de proyectos son la consecuencia de una reflexión sobre la contemporaneidad del aprendizaje de la arquitectura.

Palabras clave: Aprendizaje; arquitectura; España; proyectos; talleres;

\section{Abstract}

The theory of the architectural design (what is taught), and its methodology (how design is taught) have a remarkable tradition that is constantly enriched with new perspectives. However, when designing the studio, the pedagogical concretions are given with the specific objectives of the training (what design is taught for) and with the availability of resources (with what design is taught). This text reflects on the space and time of the architectural design studio as determining factors when it comes to shaping a design epistemology. The hypothesis is evidenced by a study case: a pedagogical unit from the the Valencia Architecture School is analyzed, which could well be representative of other Spanish schools. The results show that the specific activities that accompany the student in the design studio are the consequence of a reflection on contemporaneity in the learning of architecture.

Keywords: Architectural Design; architecture; design studio; learning; Spain

\section{Introducción: los estudios y la profesión}

La disciplina de proyectos arquitectónicos se identifica con la propia profesión. Formulado muy someramente, ser arquitecto es ser capaz de concebir un diseño susceptible de convertirse en una edificación. Esta acción tiene lugar, principalmente, en el área de conocimiento del proyecto arquitectónico, escenario donde convergen saberes - múltiples y variados- que, sumados a los propios, caracterizan el ejercicio de la arquitectura (Llorente, 2000).

En los más de 150 años de estudios reglados de arquitectura en España, los diferentes planes de estudio han incorporado ampliamente otras materias, desde saberes humanísticos hasta conocimientos técnicos; sin embargo, la alquimia que proporcionaba al estudiante la capacidad de idear, trazar y proponer los medios para ejecutar un edificio se produce en los talleres de proyectos. Tal y como señala Linazasoro en Apuntes para una teoría del proyecto, "la asignatura de proyectos no es un punto de vista más del objeto arquitectónico, sino un análisis del objeto completo" (1984, p. 22). 
En la actualidad, la formación y el ejercicio de las actividades profesionales del arquitecto en Europa se recogen en la Directiva de la Unión Europea sobre cualificaciones profesionales, y en ella se especifican cuestiones relativas a la duración, el contenido y la comprobación de las 11 competencias requeridas para el ejercicio de la profesión. El artículo 46 señala que la primera competencia es la "aptitud para crear proyectos arquitectónicos que satisfagan a la vez las exigencias estéticas y las técnicas" (Directiva 2005/36/CE, 2005, p. 47).

El Espacio Europeo de Educación Superior (EEES) es el plan que regula el proceso de convergencia europea en materia de educación superior, y en el caso de la formación en arquitectura, 401 centros europeos - 32 de los cuales son escuelas españolas - se adscriben a este a la hora de diseñar sus planes de estudio; no obstante, España cuenta con 3 particularidades relevantes. En primer lugar, aunque en toda Europa los niveles formativos son tres — grado, máster y doctorado-, en España el grado y el máster de arquitectura tienen una duración diferente. Mientras que la estructura habitual en las escuelas europeas es de 3 años de grado y 2 de máster en arquitectura, las escuelas españolas adoptan el esquema de 5 años más uno. La segunda particularidad es que los egresados del máster de arquitectura en España están capacitados para desempeñar actividades profesionales sin otro tipo de formación o práctica profesional; es decir, el máster habilita para el ejercicio de la profesión. Por último, la Ley de Ordenación de la Edificación señala que tanto el proyecto como la dirección de las obras de edificación son de la exclusiva competencia de los arquitectos.

Estos dos últimos puntos son cruciales para entender la formación en arquitectura en España, ya que determinan los planes de estudios; es decir, los contenidos que deben abordarse para afrontar un mercado profesional. Por ello, este texto plantea una reflexión específica en torno a la enseñanza del proyecto arquitectónico, la cual se modela a partir de los medios y los recursos disponibles en las escuelas de arquitectura con base en los objetivos profesionales. Aún resguardada bajo el paraguas común de una teoría del proyecto y de una tradicional metodología de taller, la docencia aplicada se ejemplifica aquí con el caso de una unidad docente adscrita al Departamento de Proyectos Arquitectónicos de la Escuela de Arquitectura de Valencia.

\section{Metodología: teoría y método de la enseñanza del proyecto arquitectónico}

\section{Naturaleza del proyecto arquitectónico}

Dice José Antonio Marina, en Teoría de la inteligencia creadora (1993), que proyectar caracteriza a la inteligencia humana, y que no es otra cosa que anticipar un objetivo por parte de un sujeto. Las acepciones del término proyecto son amplias, pero cuando este se refiere al proyecto arquitectónico, aquello que anticipamos alude tanto el espacio construido como a su forma de ocuparlo; consecuentemente, el recorrido hasta él debe diseñarse escrupulosamente, porque encierra muchos contenidos e innumerables dualidades. Es sabido por todos los arquitectos que el proyecto arquitectónico actúa de puente entre muchos polos: cubre la distancia entre la teoría y la práctica, abarca saberes del ámbito de las ciencias y de las artes, y requiere un discurso racional, a la par que una respuesta sensible.

Así mismo, el proyecto no es en un momento determinado, sino que ocurre durante un arco temporal que finaliza, en términos de realidad, con la obra acabada. Dicho de otro modo, el proyecto es igualmente en los arranques — cuando apenas una idea de forma o una disposición funcional están siendo esbozadas - que en los remates — cuando se ensayan soluciones técnicas alternativas por un motivo determinado: porque la naturaleza del proyecto se mueve entre una idea (o varias) y una realidad construida, objetivo sin el cual pierde su sentido- - Durante su evolución se combinan etapas de proposición y de comprobación, y también se suceden procesos de aplicación de conocimientos con su más consciente desinhibición de cualquier condicionante externo.

Hay otros muchos aspectos que caracterizan al proyecto: comunicarlo le sienta bien porque ayuda a repasar su narrativa, es difícilmente repetible en un contexto diferente $y$, más aún, para un mismo programa de necesidades y un entorno puede haber varios proyectos igualmente satisfactorios. En definitiva, el proyecto es un equilibrio heterodoxo de elementos donde una minúscula modificación puede alterar grandes trazas del diseño, y algunas líneas de investigación se centran en representar gráficamente estos complejos procesos (Goldschmidt, 2014).

\section{Proyecto arquitectónico y conocimiento}

¿Qué conocimientos son necesarios para proyectar? ¿Cómo se utilizan esos conocimientos? ¿Se genera conocimiento al proyectar? Aunque son preguntas ambiciosas cuyas respuestas corresponden a los especialistas en la materia, algunos argumentos pueden aspirar a exponerse de forma sintética. La historia de la arquitectura ha discurrido en paralelo con los debates de la propia evolución de la teoría del conocimiento: por un lado, la constante tensión entre los resultados de la extracción de datos de la experiencia o de los diferentes intelectualismos (asimilación del conocimiento desde el terreno de la práctica o de la teoría); por otro, la nebulosa acotación, el uso y la adopción de reflexiones de disciplinas tangentes (que introducen, y además fácilmente, cualquier atisbo de veracidad).

Desde los orígenes de la teoría arquitectónica hasta la actualidad, las tesis han oscilado entre argumentos realistas y visiones idealistas. Los primeros 


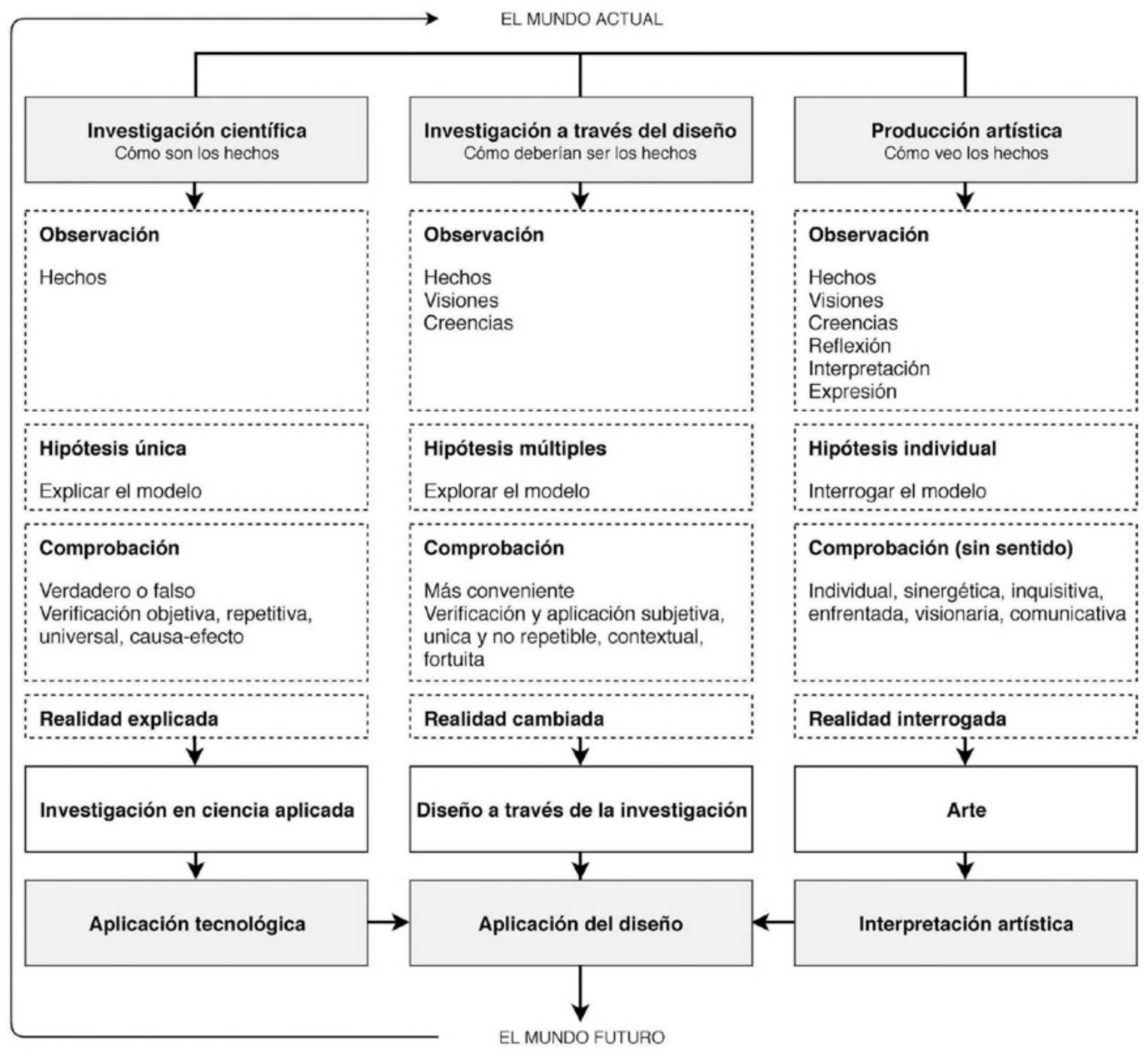

* Figura 1. Comparación y aplicaciones de la investigación científica, la investigación a través del diseño y la producción artística.

Fuente: Richard Foqué (2010). Adaptación y traducción: elaboración propia (2018). reducen el papel del arquitecto a la producción: enunciados categóricos, leyes proporcionales e imitaciones formales, que minimizan la participación del sujeto cognoscente en el resultado final. En el extremo opuesto, los idealismos achacan al autor toda la capacidad creativa, y olvidan el papel de interlocución que puede llegar a tener el objeto/obra. Por ejemplo, durante la tradición clásica dos eran los factores que determinaban el sistema del proyecto: la mímesis y la existencia de unas leyes proporcionales definidas a priori; sin embargo, al cierre del siglo XVIII y durante todo el siglo XIX, y en claro paralelismo al pensamiento filosófico moderno, con la aparición del sujeto como punto de arranque se sustituyó, en algunos casos, la base empírica por leyes objetivas, y en otros emergieron con fuerza los argumentos subjetivos. La llegada al siglo XX se definió por el aferramiento a los procesos racionalistas, positivistas y cientificistas (componente tecnológico y confianza en los valores políticos y sociales), a los que se trató de desmantelar con el pensamiento posmoderno aludiendo a pluralismos y complejidades en la interpretación del mundo real (Domingo-Calabuig, 2005).

En Building Knowledge in Architecture, Richard Foqué (2010) alude a la situación actual como la "paradoja de la posmodernidad". En un orden jerarquizado de saberes, la arquitectura se ha querido alinear con el conocimiento científico y el discurso racional, contextos donde se producen la especialización y los provechosos avances, y por ello su docencia y su investigación se incluyen en las instituciones universitarias; no obstante, este hecho conduce a un distanciamiento de su aspecto disciplinar como profesión, pues pierde su condición de conocimiento integrado y su capacidad de respuesta práctica a las necesidades comunes.

De este modo, podría decirse que en la puesta en valor del conocimiento generado en el proceso de proyecto — en su sentido más creativo-y en la eliminación de la tensión entre conocimiento científico y conocimiento artístico residiría la clave para una evolución de la disciplina y una recuperación de la profesión. Efectivamente, el proceso de proyecto aúna los opuestos de una indagación científica (observación, inducción, deducción, comprobación, evaluación) y de una experimentación artística (reflexión sobre la realidad, reacción frente a los hechos, expresión...); es en la frontera entre el pensamiento racional y el intuitivo donde se produce el momento creativo del diseño o del proyecto arquitectónico, como se expone en la figura 1.

\section{El taller de proyectos}

La enseñanza actual del proyecto arquitectónico no resulta comprensible sin asumir las consecuencias de algunos momentos pedagógicos históricos que han sido relevantes por sus planteamientos y sus reflexiones. Sin necesidad de retroceder más allá de los últimos 100 años, se deben subrayar los acercamientos a la disciplina que se inculcaron en la Bauhaus y la Escuela de Ulm. Adicionalmente, el sistema docente de la formación francesa en 
arquitectura (Lambert, 2014), su influencia en la pedagogía americana (Ockman et al., 2012) y las transformaciones de la enseñanza tras los acontecimientos del 68 también ayudan a vislumbrar de qué ingredientes se compone el panorama actual.

El panorama educativo tradicional, de herencia academicista, puede esbozarse en Francia, país que exportó su formación adscrita al sistema de Beaux-Arts y su pedagogía de ateliers a los países anglosajones (Harris, 2015). Durante el siglo XIX, los alumnos recibían conjuntamente una docencia teórica en las aulas-anfiteatro, pero se formaban en la práctica de los ateliers de artistas, unidades casi tribales, ajenas a la academia, donde el maestro-patrón les enseñaba el oficio, de lo cual se muestra un ejemplo en la figura 2. Posteriormente eran examinados por la institución, para la obtención del título. El modelo evolucionó de manera sutil, ya que, prácticamente, imperaba el mismo esquema para cuando la desaparición de la sección de arquitectura de la escuela de Bellas Artes, en 1968, supuso la refundación de los talleres en unidades pedagógicas, y estas adquirieron autonomía en el diseño de su plan de estudios. Cada unidad pedagógica se convirtió en una escuela de arquitectura, muy determinada por las convicciones de su profesor fundador; tal es el caso de Bernard Huet, cuyos escritos sobre la materia tuvieron repercusión en España durante los años la década de 1970 (Huet, 1980).

De igual modo, el espacio de la enseñanza ocupa un lugar relevante en los debates pedagógicos, de forma generalizada (Harrisson y Hulton, 2014), pero cuando este se refiere a una especi-

จ Figura 2. École Nationale des Beaux-Arts. Atelier de Jean Louis Pascal.

Fuente: Musée National de I'Éducation (1872-1920). Dominio público
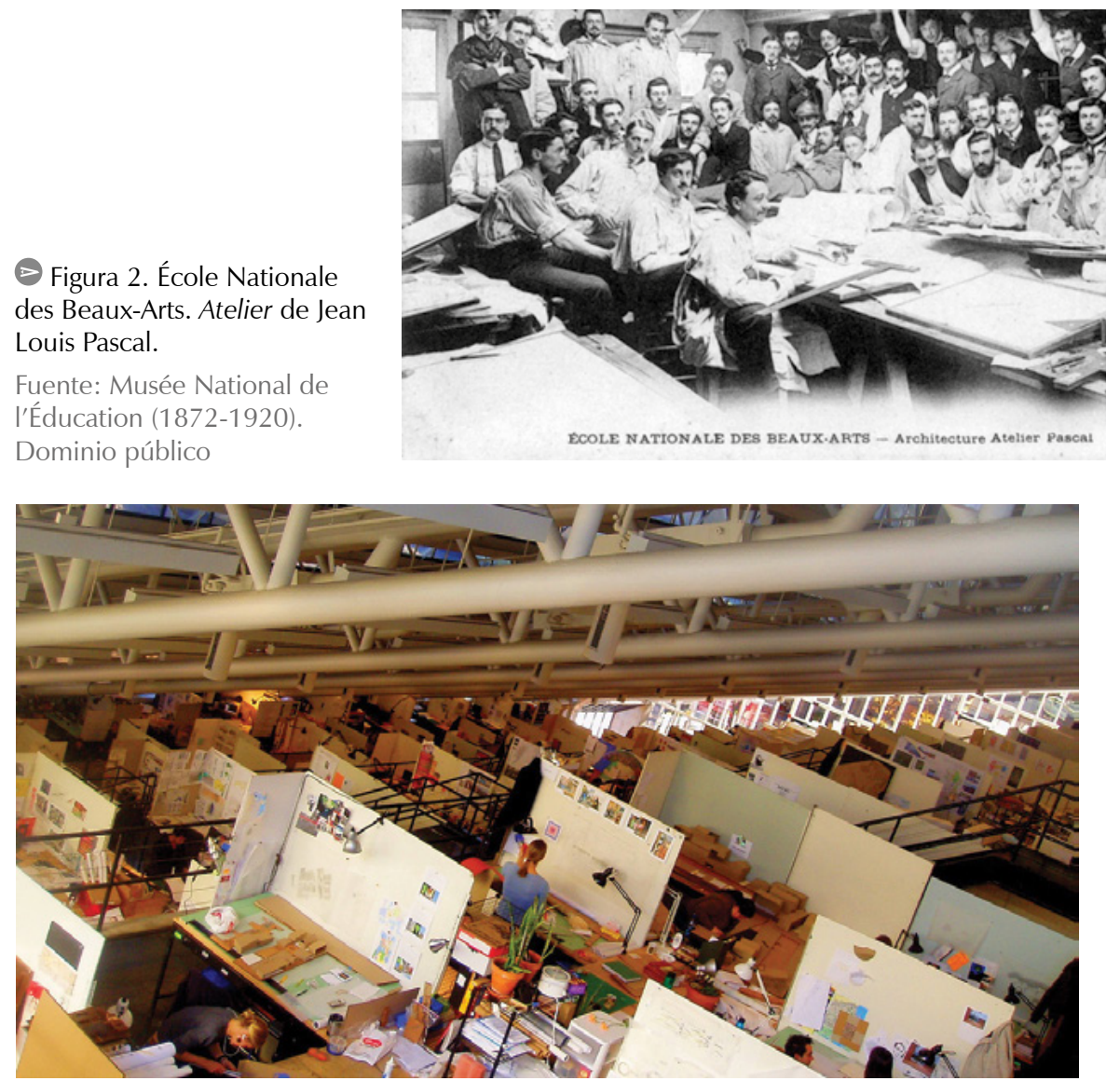

(A) Figura 3. Gund Hall's Studios. Fuente: Matt | Flickr (2006). CC BY-NC ficidad docente, como lo es el taller de proyectos, la cuestión del espacio no puede obviarse. Se atiende aquí a la condición física del espacio, pero también, a su presencia psíquica en el panorama completo de los estudios de arquitectura.

En el ámbito anglosajón, se habla de la "cultura del taller de proyectos" para referirse al taller como un espacio de trabajo, más que una simple aula. El taller es el lugar central del aprendizaje del proyecto, y su premisa operativa se basa en el trabajo continuo y autónomo, apoyado por un diálogo entre el estudiante y el profesor, así como entre los propios estudiantes. El taller es el lugar donde, durante de las horas de clase se desarrolla el trabajo - pero también, fuera de estas-. Así, las escuelas de arquitectura invierten generosos recursos económicos en proveer dichos espacios con los equipamientos necesarios. Un ejemplo significativo es el conocido Gund Hall, en Harvard University, aunque, en general, todas las escuelas cuentan con esos espacios, tan vitales para la formación de los estudiantes, como se muestra en la figura 3.

Así, el aula de proyectos y su entorno son objeto de un vocabulario específico. Los design studio o los ateliers son los lugares donde tienen lugar las charettes (concentraciones de intenso trabajo que hacen que las escuelas de arquitectura se queden abiertas en horario nocturno o en días festivos), pero también los juries, los crits sessions, los workshops o los seminars. Toda esta jerga da cuenta del sitio central que ocupa el espacio de trabajo del proyecto arquitectónico en la vida del estudiante de arquitectura. Su especificidad queda reflejada mediante numerosos testimonios fácilmente localizables en el mundo digital (blogs, guías de ayuda, repositorio de recursos...), pero también sus factores psicosociales están siendo objeto de estudios recientes (Martín Rivas, 2016).

\section{Resultados}

\section{El caso de la Escuela de Arquitectura de Valencia}

En los epígrafes anteriores del presente texto se ha abordado una visión panorámica sobre la teoría del proyecto arquitectónico (qué se enseña) y su metodología (cómo se enseña), y se han introducido las cuestiones relativas al tiempo y el espacio del taller de proyectos en la formación del arquitecto; no obstante, la hipótesis de este trabajo presupone que cuando se acometen el proyecto docente y su planificación, las concreciones pedagógicas se dan con los objetivos específicos de la formación (para qué se enseña) y con la disponibilidad de recursos (con qué se enseña), determinados, precisamente, por la temporalidad y la espacialidad de la docencia. Por ello, se analiza a continuación el caso de una unidad docente de la Escuela de Arquitectura de la Universitat Politècnica de Valencia (ETSAUPV), que bien podría ser representativa de otras escuelas de arquitectura españolas. 


\section{La ETSA-UPV y los talleres de proyectos}

La ETSA-UPV fue fundada en 1968. Son, pues, más de 50 años de trayectoria, durante los cuales que se han impartido hasta 5 planes de estudio; el plan vigente es el aprobado e iniciado en 2014. Salvo en el primer curso de los primeros planes, la docencia de proyectos arquitectónicos ha estado presente en todos los cursos, y sus asignaturas han aunado el mayor porcentaje de créditos docentes, como se explica en la figura 4.

Como consecuencia de la convergencia hacia el EEES, los estudios de arquitectura son ahora un programa académico integrado por el Grado en Fundamentos de la Arquitectura, de 5 cursos y 300 de European Credit Transfer and Accumulation System (ECTS) (60 ECTS por curso) y el Máster en Arquitectura, de un curso de duración y 60 ECTS, titulación que habilita para el ejercicio de la profesión. Las asignaturas de proyectos arquitectónicos se imparten anualmente y son troncales u obligatorias, tal y como se muestra en la figura 5.

El Departamento de Proyectos Arquitectónicos de la ETSA-UPV organiza su docencia mediante grupos de profesorado, o unidades docentes, que coloquialmente reciben el nombre de talleres. En la actualidad, existen 7 grupos (Taller 1, Taller 2, Taller 3, Taller 4, Taller 5, Taller A y Laboratorio H), los cuales se rigen por un reglamento interno que vela por su triple naturaleza: el taller es un sistema organizativo que aglutina a un número de profesores; es también el espacio docente donde se desarrolla una metodología de aprendizaje en común; es una opción docente para el estudiante, quien puede elegir entre tantos grupos como talleres existen en función de sus intereses personales. Dicha estructura es claramente eficiente en términos de comunicación y de trabajo en equipo: debe entenderse que el departamento imparte docencia a prácticamente todo el alumnado de la ETSA-UPV y cuenta actualmente con más de 85 profesores.

Además de lo anterior, en el taller se permite la docencia de forma tanto vertical (aunando en el aula algunos o todos los niveles) como horizontal (impartiendo docencia por niveles). En el caso que nos ocupa - el Taller 2-, la docencia es vertical y colegiada: 2 profesores comparten sus grupos, de 25 estudiantes cada uno, que provienen de los niveles de Proyectos 2 hasta Proyectos 5 (segundo, tercer, cuarto y quinto cursos). En el modelo de docencia en vertical, la riqueza docente deviene de la convivencia entre personas con diferentes niveles de conocimiento, y las dinámicas de trabajo se asemejan más a la realidad de un taller formativo, o, incluso, profesional.

\section{Programación de la actividad docente}

Las memorias docentes de todas las asignaturas de los planes de estudio del grado y los másteres impartidos en la ETSA-UPV son documentos de libre acceso que definen brevemente los objetivos formativos y las competencias, al igual que esbozan los contenidos del curso. Sobre la base de estos

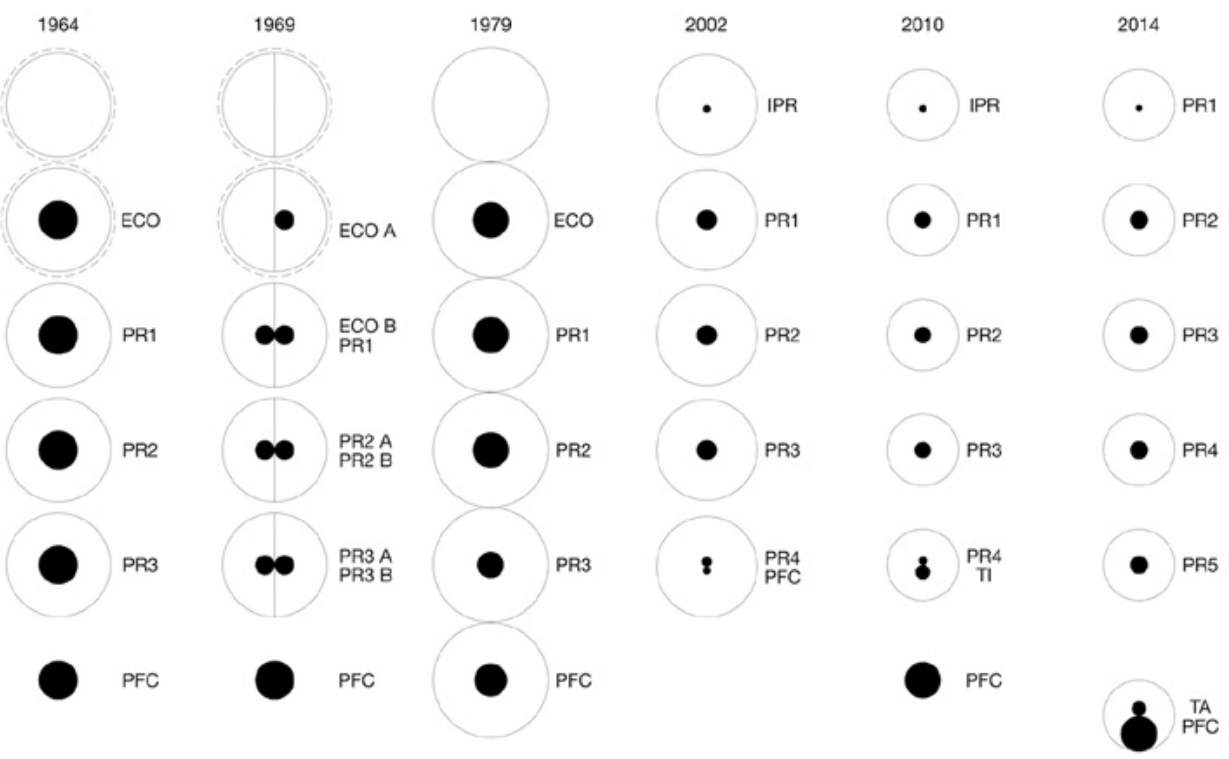

(A) Figura 4. Comparativa créditos/horas de las asignaturas de proyectos en los planes de estudio de la ETSA-UPV.

Fuente: elaboración propia (2018).

ESCUELA TÉCNICA SUPERIOR DE ARQUITECTURA - UPV

GRADO EN FUNDAMENTOS DE LA ARQUITECTURA - PLAN 2014
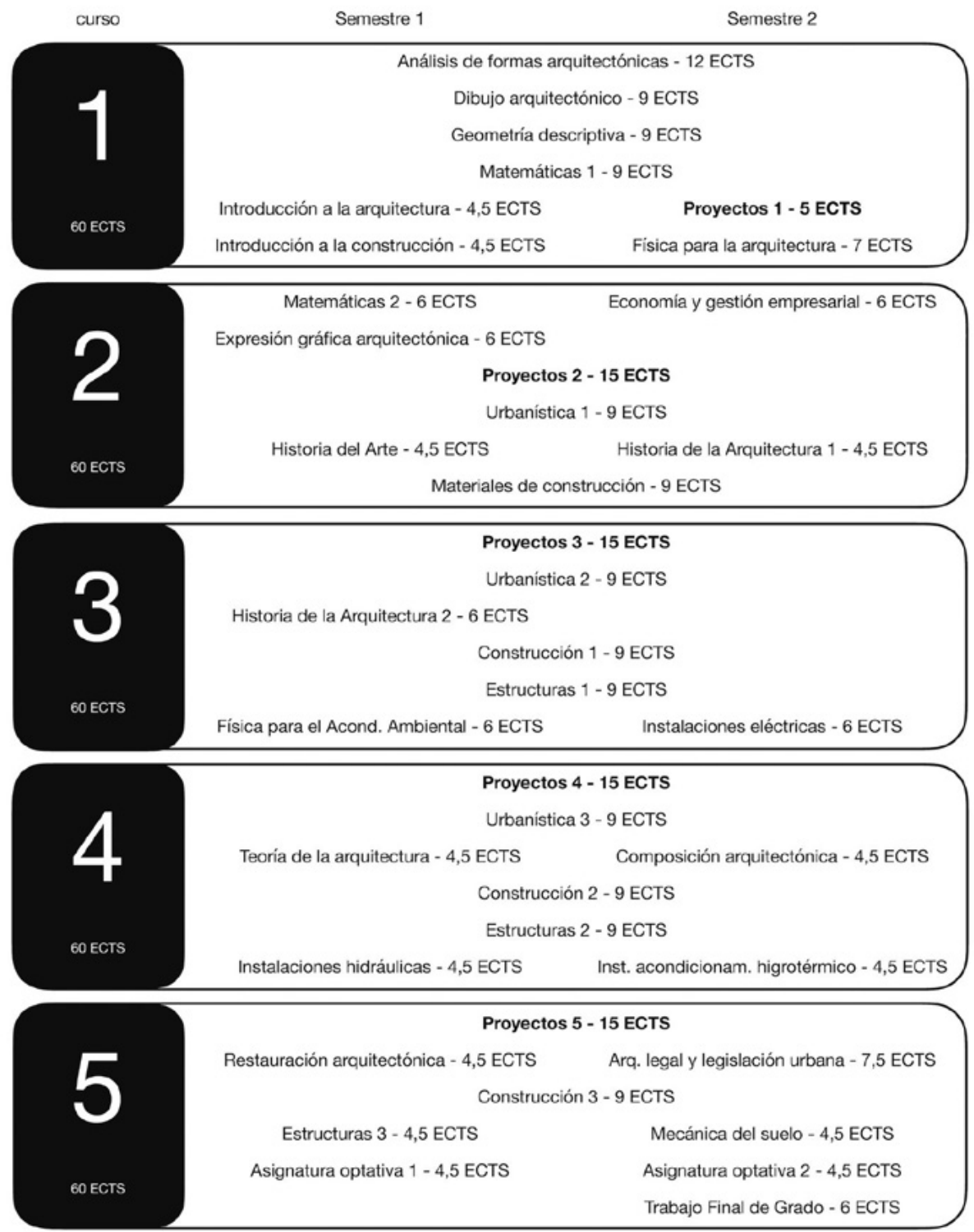

(A) Figura 5. Esquema gráfico del Grado en Fundamentos de la Arquitectura en la ETSA-UPV. Fuente: elaboración propia (2020). 

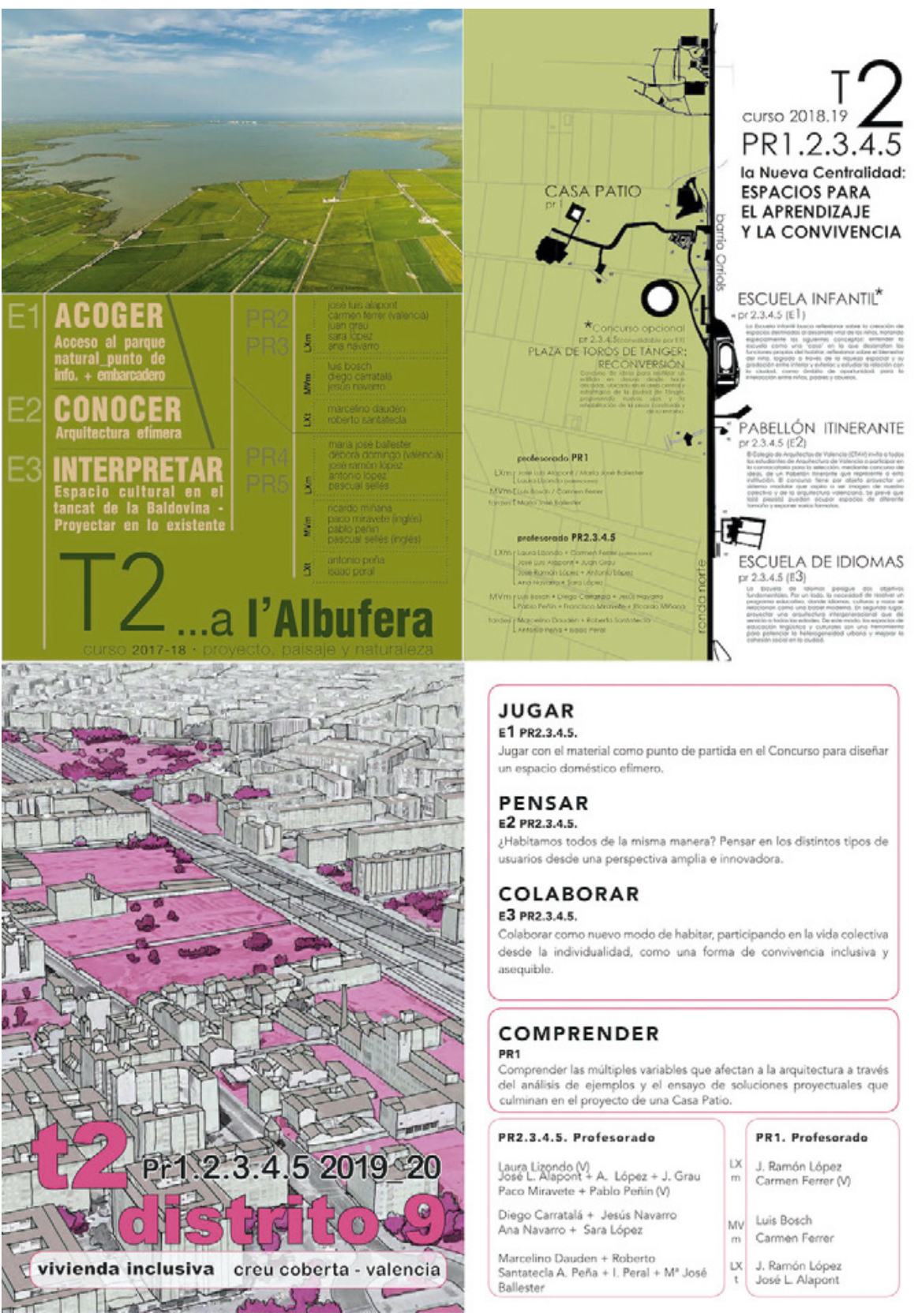

(A) Figura 6. Carteles de diferentes cursos académicos del Taller 2 de la ETSA-UPV.

Fuente: elaboración propia (2019). objetivos, el profesorado de proyectos diseña un programa concreto de curso, una estructura de trabajo u hoja de ruta docente que se concreta con unos ejercicios particulares adscritos a una temática. La puesta en práctica del mismo proyecto resulta ser la forma más adecuada para su aprendizaje: más allá de abordar un tradicional temario de lecciones, el estudiante debe ejercitar diferentes diseños de complejidad creciente que simulen el acercamiento a un proyecto real. Es importante diferenciar bien toda esta terminología para no incurrir en simplificaciones: a un objetivo formativo se puede llegar con diferentes programas de cursos, concretados con muy variados ejercicios. Aquí reside la riqueza de la docencia del proyecto arquitectónico: en que cada ejercicio sea, a su vez, un proyecto en sí mismo, orientado hacia el conocimiento y la solución de problemas urbanos, paisajísticos y arquitectónicos reales. Esta forma de programar y modificar los enunciados cada año académico es una oportunidad para reflexionar los planteamientos docentes, a fin de propiciar la ilusión y poner en marcha los mecanismos creativos de docentes y estudiantes.

Los ejercicios de proyectos se formalizan entonces mediante enunciados que contienen las varia- bles de contexto (lugar, emplazamiento, pero también circunstancias ambientales o materiales), de un programa funcional (o los datos que pueden servir para deducirlo), y una acotación temporal. Cada ejercicio de proyectos tiene un tiempo limitado (como en la vida real), durante el cual el estudiante debe ser guiado por el docente en el logro del objetivo (enunciación, ideación, desarrollo...).

\section{Propuesta de curso académico y resultados metodológicos del taller}

Recogiendo los objetivos formativos de las asignaturas que se imparten mediante una metodología de taller vertical, desde Proyectos 2 a Proyectos 5 , el equipo docente del Taller 2 plantea una propuesta de curso académico que introduzca una temática de interés, según circunstancias contextuales, ambientales o programáticas específicas. Consecuentemente, la temática no es monográfica, sino que se establece de acuerdo con las circunstancias de cada año; tampoco, el lugar de trabajo, el cual varía de forma cíclica, a fin de que los estudiantes tengan una formación lo más completa y coordinada posible, abarcando circunstancias urbanas y paisajística diversas.

La estructura — similar de un año a otro- atiende al desarrollo de tres ejercicios; cada uno, con objetivos y características diferentes, según se aprecia en la figura 6 . El equipo docente se organiza también por grupos adscritos a cada uno de los ejercicios para preparar profundamente los enunciados y la planificación de actividades correspondientes.

El primer ejercicio del curso se desarrolla individualmente, y abarca el trimestre de otoño, desde septiembre hasta diciembre: un periodo marcado por la ilusión del arranque del curso. Por lo general, se trata de un proyecto de nueva construcción y de tamaño medio que implique una reflexión sobre las condiciones de entorno. El lugar de implantación pertenece al emplazamiento global donde el alumno trabajará a lo largo del curso; también, la tipología edificatoria, la cual, a su vez, atenderá a un hilo conductor común -arquitectura residencial, docente, sanitaria, cultural...-. De ese modo, este primer enunciado supone una primera aproximación contextual, social y funcional.

El segundo ejercicio se caracteriza por ser breve, en grupo vertical y con un formato de concurso. Esta experiencia cambia la dinámica del curso, por lo que es acogida con mucho entusiasmo por los estudiantes: se acercan a un ámbito profesional, trabajan codo a codo con compañeros de otros niveles y aspiran a la posibilidad de construir realmente la pieza proyectada si resultan ganadores del concurso. El enunciado permite objetivos formativos muy específicos, relativos al trabajo en equipo (liderazgo, mediación, reparto de responsabilidades), la reflexión del proyecto como espacio/objeto construible, el trabajo en maqueta y la representación gráfica como herramienta fundamental para transmitir la arquitectura. Se trata de un aprendizaje especialmente atractivo, pues a lo largo de este, los alumnos construyen prototipos, experimentan 
con materiales e investigan en los diferentes oficios que les permitan construir la idea arquitectónica. Además, como se suele tratar de una pieza compleja de mobiliario o de alguna instalación efímera construible, el proyecto debe ajustarse a un presupuesto determinado, y por ello entran en escena cuestiones materiales y económicas.

Con el tercer ejercicio se vuelve a la concentración del ejercicio individual, y para esta última etapa se busca una temática adscrita a la reutilización de edificaciones existentes. Se aborda así un ámbito de proyecto: el de la intervención en el patrimonio construido y el reciclaje de la edificación, cuya oportunidad supone también un compromiso profesional. El lugar y la temática tienen relación con lo ya cursado, pero en esta ocasión el proyecto tiene una escala y una envergadura mayores en el territorio. Al margen de la tipología específica, son importantes las consideraciones en torno al papel que los edificios de gran escala desempeñan en la lectura de una ciudad, su capacidad para fijar determinados acontecimientos en la historia de un determinado barrio, o de la metrópoli entera, y su carácter emergente dentro del contexto urbano.

Para el desarrollo de los tres ejercicios se requieren ciertas actividades docentes que se optimizan para todo el taller, siguiendo una pauta que responde a una estructura de programación genérica, tal como se muestra en la figura 7. Los ejercicios comienzan con unas clases teóricas, en las que se presenta el enunciado (acompañado del calendario de trabajo, los criterios de evaluación...) y una visita al emplazamiento; ambas actividades pretenden propiciar una reflexión sobre la temática y el contexto. Todo ello se complementa con clases teóricas específicas sobre cuestiones particulares y algunas conferencias. El planteamiento general de la asignatura alterna actividades conjuntas e individuales; estas últimas, entendidas como aquellas en las que cada profesor organiza sus clases con los estudiantes de su grupo. En el tiempo de las sesiones individuales no solo se hacen las revisiones de los proyectos en curso, sino que se llevan a cabo actividades expresamente diseñadas para incidir en aspectos específicos, y las cuales son propias del nivel de la asignatura, clases de apoyo, que llegan a quedar reflejadas en blogs particulares de los docentes: minilecciones específicas, ejercicios de proyecto complementarios para desarrollar o enfatizar algún aspecto o carencia, recomendaciones de lecturas y debates, como se expone en la figura 8 . Respecto de las revisiones de los trabajos, se desarrollan sesiones de crítica, siempre de forma abierta con todo el grupo, y es en este último círculo de relación docente donde se genera la complicidad necesaria para atender o solventar cuestiones particulares, según se ve en la figura 9 .

Adicionalmente, el calendario contempla una o varias entregas intermedias, que se aprovechan para celebrar sesiones de crítica colectiva entre varios grupos de profesores, donde, en ocasiones, se incorporan profesores invitados.

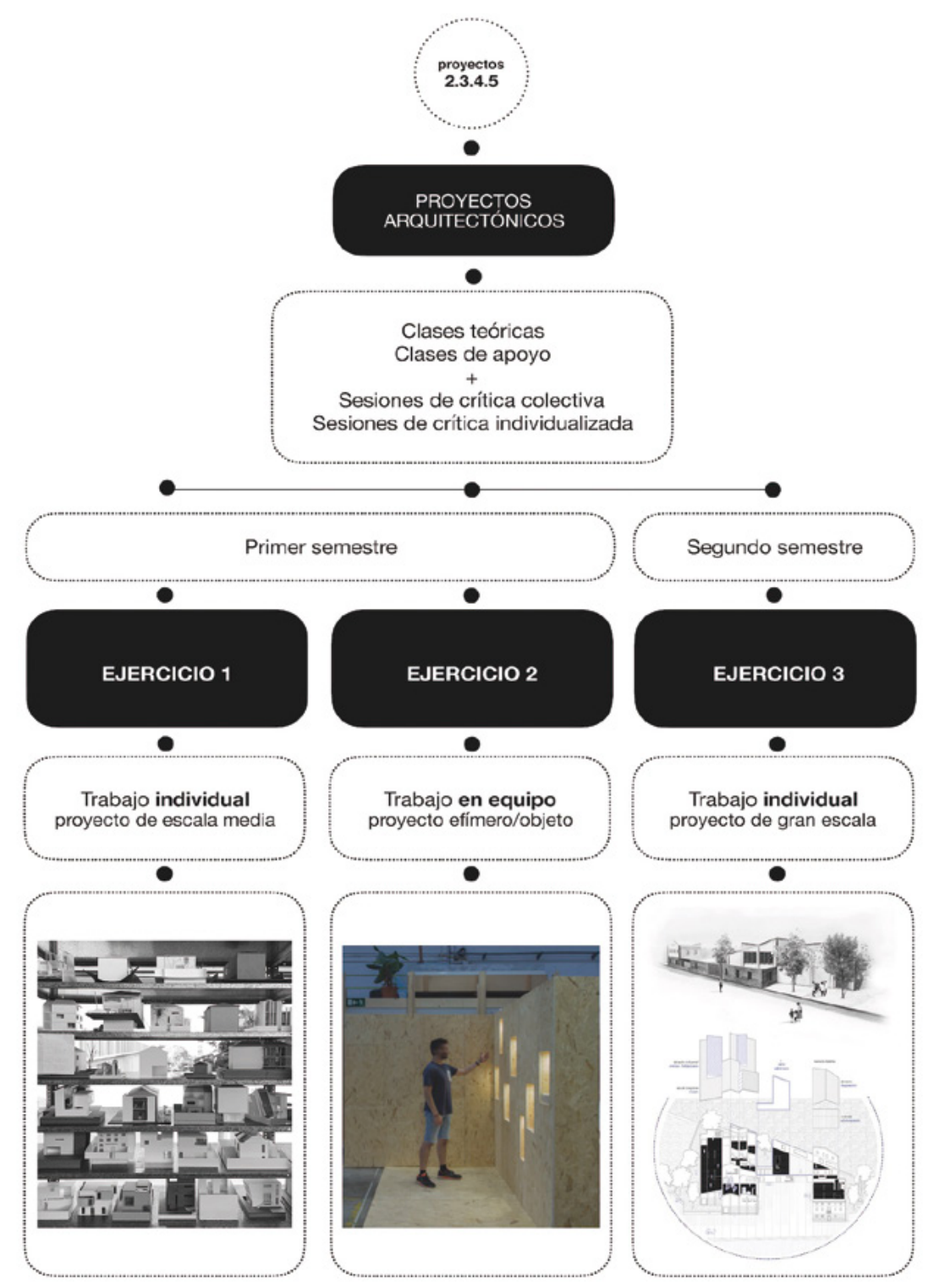

Los resultados obtenidos en cada uno de los ejercicios muestran los aprendizajes específicos de cada enunciado y cada nivel proyectual. En el primer ejercicio, por ser programáticamente más sencillo, se trabaja a partir del dibujo a mano y la maqueta tridimensional, a raíz de lo cual se obtienen proyectos en los que priman el concepto espacial y volumétrico del proyecto y la visión analítica del contexto. Los estudiantes de los primeros cursos experimentan con nuevas metodologías y complejidades, y los alumnos de niveles más avanzados aparcan momentáneamente las herramientas digitales para testear, de forma ágil, su capacidad de respuesta a corto plazo en lo que a la génesis y la formalización del proyecto se refiere.

En el segundo ejercicio se obtienen resultados relacionados con el trabajo en equipo, con un alto nivel de interacciones entre pares y una simulación clara de un ambiente competencial profesional; por ello, los proyectos propuestos son viables constructiva y económicamente, y planteados a partir de un argumento descriptivo-gráfico sugerente y una definición a escala de detalle.

El tercer ejercicio, por su extensión y su desarroIlo individual, evidencia los logros, de acuerdo con
A Figura 7. Esquema de los tres ejercicios de curso del Taller 2.

Fuente: elaboración propia (2019). 
el curso en el que se ubica cada estudiante. En relación con los estadios de un proceso de diseño, se repiten las primeras etapas producidas en el primer ejercicio, y a las cuales se suman otras relativas a los niveles de conocimiento: los estudiantes de los primeros cursos plantean un proyecto definido hasta su materialización (esquema estructural y texturas), mientras que los de cursos superiores lo desarrollan estructural y constructivamente.

\section{Discusión}

A modo de crítica e interpretación de los datos expuestos, se retoman algunas cuestiones resultantes del análisis del caso de la estructura docente Taller 2 de la ETSA-UPV, a fin de señalar eventuales extrapolaciones y comparaciones con futuros estudios. En primer lugar, el Taller 2 ha apostado por un planteamiento de docencia vertical: la convivencia en el aula de varios niveles formativos deviene en el enriquecimiento de las discusiones. Tal y como ocurría en los antiguos ateliers de las academias, los estudiantes más jóvenes se nutren al compartir su experiencia proyectual con los más experimentados; así mismo, la labor tutelar de los alumnos de cursos superiores los obliga a realizar un ejercicio de racionalización inherente, por lo cual es sugestivo comprobar la propia madurez alcanzada a través de los cursos. Dicha estrategia pedagógica favorece al aprendizaje activo entre estudiantes, sin perder de vista la consecución de las compe- tencias específicas correspondientes a cada uno de los niveles de la asignatura; sin embargo, y en aras de una actualización del contexto académico, aquí la figura del patrón del taller pierde relevancia y se aboga por una enseñanza colegiada (dos docentes con dos grupos de estudiantes), que desfocaliza la figura del profesor, y por ofrecer un debate con apertura de miras.

Por otro lado, la elaboración de pequeños ejercicios en grupo, formados por estudiantes de cursos variados, aproxima a un marco profesional de trabajo en equipo. Es este el lugar docente donde se intensifica el control de las competencias transversales (Riesco, 2008); especialmente, las relativas al trabajo en equipo y el liderazgo, a la comunicación efectiva y a la planificación y la gestión del tiempo. La Universitat Politècnica de València cuenta con un proyecto institucional para el desarrollo de dichas competencias, y se cumple así con la evaluación de los resultados de aprendizaje (Universitat Politècnica de València, 2015).

Por último, la unidad docente pone en práctica la reformulación metodológica del aprendizaje basado en proyectos (ABP), claramente auspiciada por la convergencia de los estudios superiores hacia el EEES. Este método de enseñanza, en el que los estudiantes adquieren conocimientos y habilidades al trabajar durante un periodo prolongado para investigar y responder a una pregunta o un problema auténtico, atractivo y complejo, es considerado
Fuente: elaboración propia (2019).

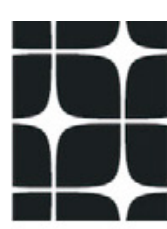

t2-

proyectos

1.2.3

curso 2013.14 - ataniv - prot. dobora
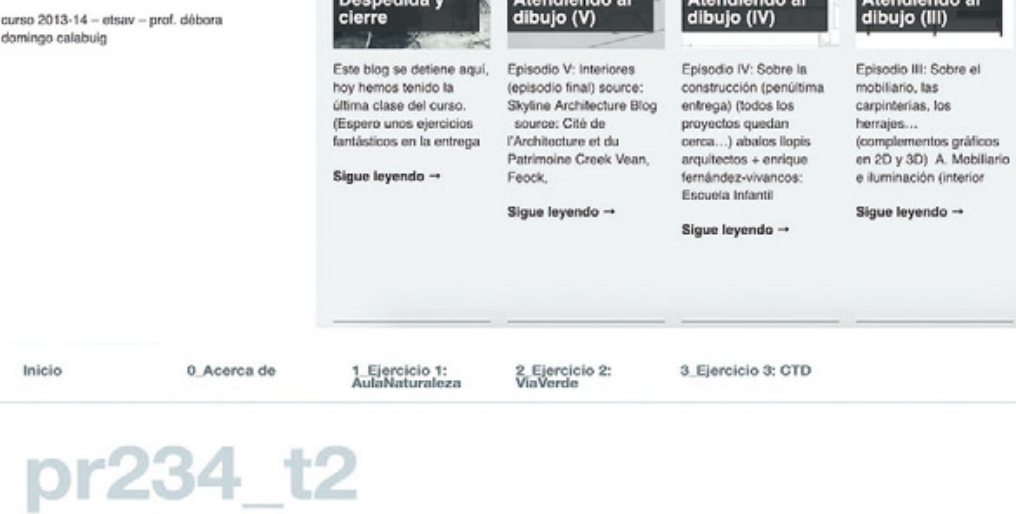

curso 2014/15 _ laura lizondo
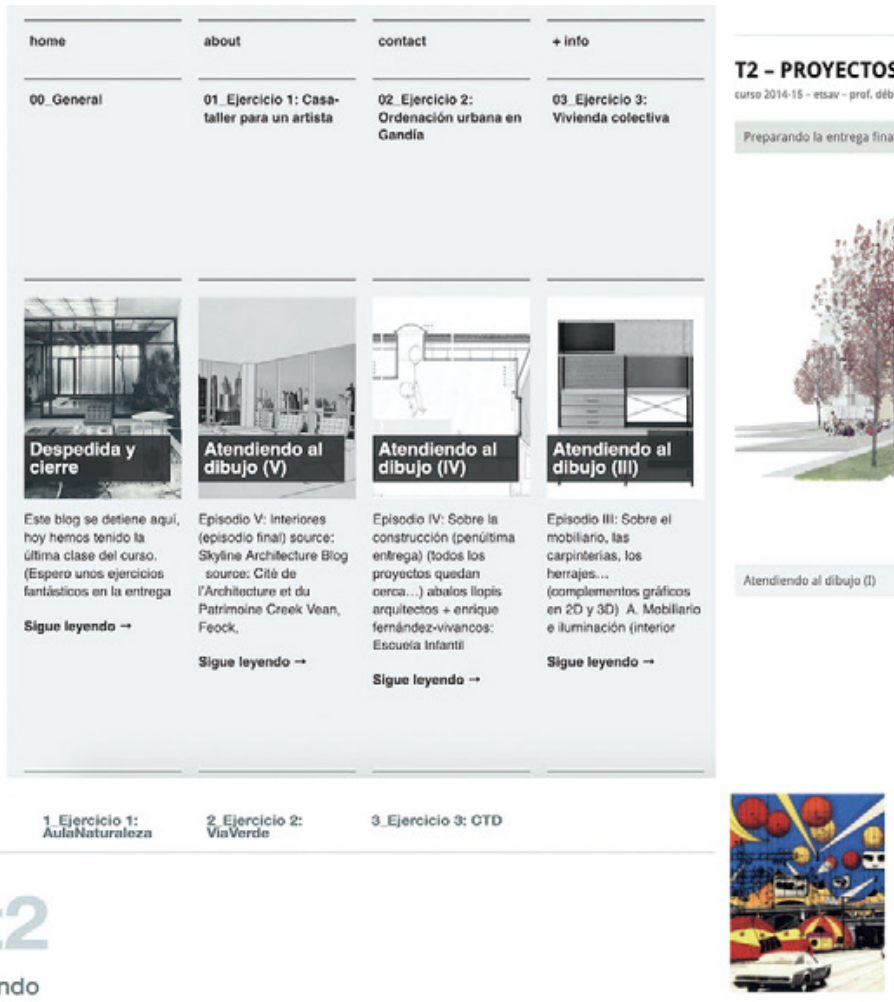

\section{2_Bibliografía}

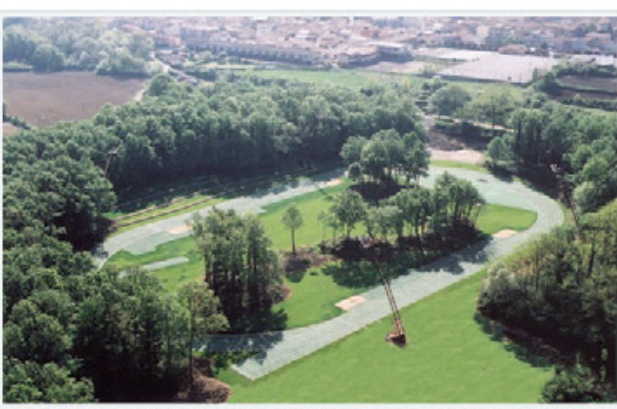

pr23t2

-

TIPOLOGIÁ DEPORTIVA

LLizonse. 201512016
T2 - PROYECTOS 2.3.4

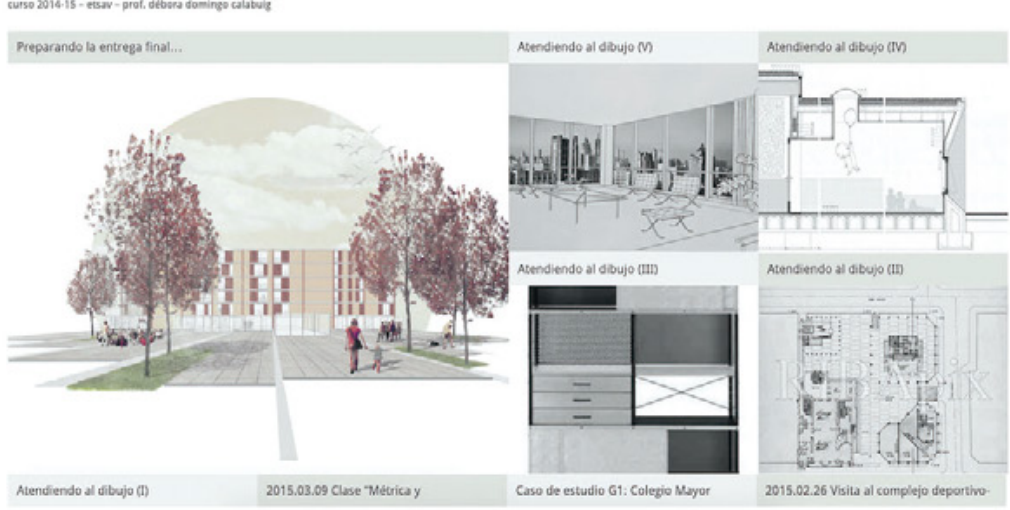

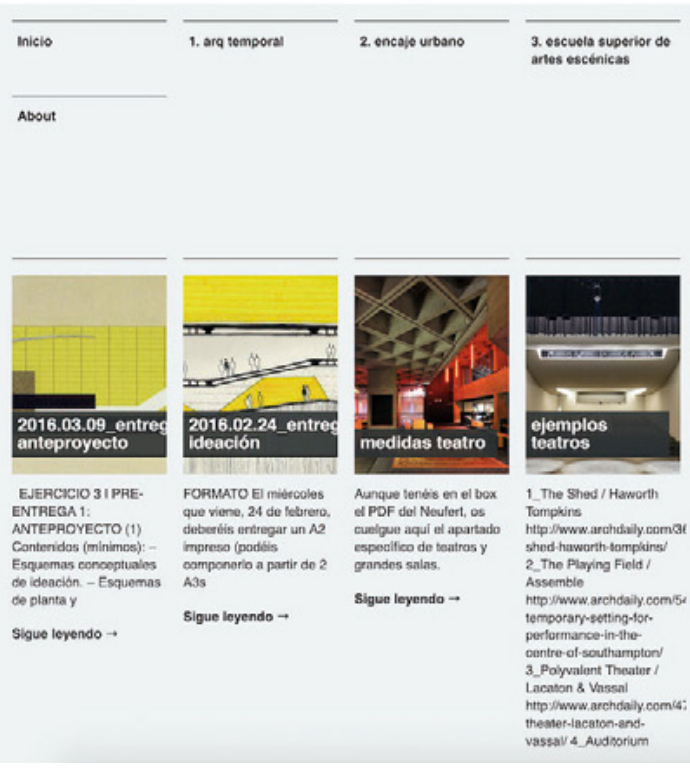


uno de los métodos del aprendizaje activo, también definido como "aprender a hacer, haciendo" (Thomas, 2000). En el Taller 2 de la ETSA-UPV, esta metodología docente se imparte desde los primeros cursos, con resultados altamente satisfactorios (Lizondo, 2019). Sin desdeñar el formato de clase teórica tradicional (conferencia), en el que un orador transmite (información y pasión por una temática) y el estudiante simplemente se nutre de ella, otras técnicas docentes que abogan por "dar clase con la boca cerrada" (Finkel, 2008) promulgan la disolución de la figura del profesor, en aras de una mayor autonomía reflexiva del estudiante. Combinar diferentes tipos de actividades resulta en el enriquecimiento de la docencia del proyecto.

\section{Conclusiones}

En la ETSA-UPV, la docencia vertical planteada por el Taller 2 puede mostrarse como un ejemplo significativo de una herencia histórica del aprendizaje en talleres, una adaptación metodológica a las circunstancias contemporáneas y una concreción pedagógica optimizada para unos fines formativos y unos recursos concretos.

Desde que las escuelas de arquitectura españolas fueron incluidas en las universidades politécnicas en 1969 (Madrid, Barcelona, Valencia), la formación se ha situado en la dicotomía entre ciencia y profesión. En este sentido, el Taller 2 programa su docencia siempre ligada a problemáticas contextuales y plantea enunciados de trabajos que se acercan al trabajo real del arquitecto: (emplazamientos concretos, situaciones reales, trabajo en equipo organizado según diferentes niveles de conocimiento, convocatoria a concursos, reutilización del patrimonio construido, convenios con instituciones públicas y privadas...). Consecuentemente, las aulas de proyectos, aunque cómodamente equipadas, no son un lugar permanente de

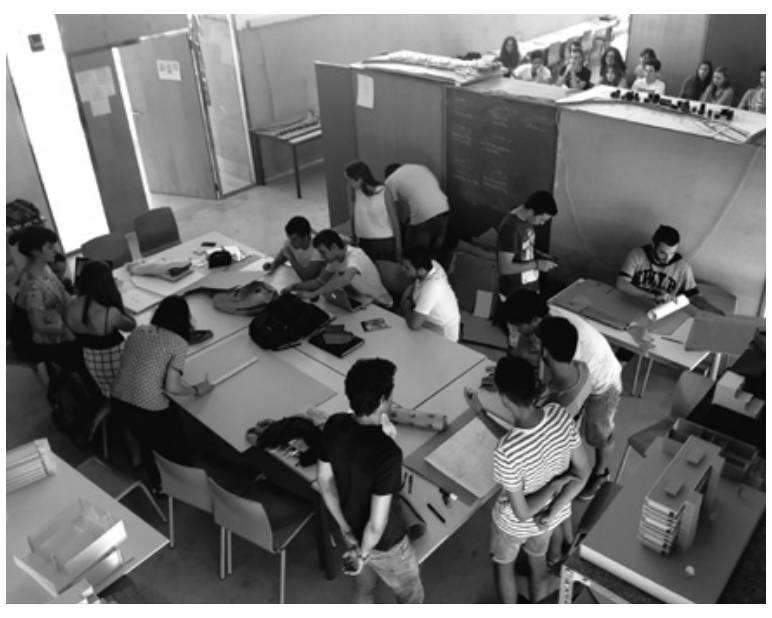

(4) Figura 9. Aula taller de la ETSA-UPV.

Fuente: elaboración propia (2016).

trabajo del alumnado; los lugares específicos de cada ejercicio, el laboratorio de construcción de maquetas y las visitas programadas convierten el taller de proyectos en un lugar de paso. Tiempo acotado y espacio no permanente deben compensarse con métodos docentes que aporten iguales valores.

\section{Contribuciones}

Las autoras de este escrito han impartido el mismo programa docente para grupos paralelos de estudiantado en el seno de la unidad docente objeto de estudio; por lo tanto, la adquisición de los datos, su análisis y su discusión son totalmente compartidos. Respecto de la redacción del texto, una de las autoras ha desarrollado la primera versión escrita, mientras que la otra se ha encargado de las sucesivas versiones, al tiempo que se compartían las revisiones críticas. La elaboración de imágenes también resulta equilibrada: los diagramas de las figuras 1,4 y 5 han sido realizados por una autora, y el diagrama de la figura 7 fue dibujado por la otra, quien se encargó, además, de la edición de todas las imágenes.

\section{Referencias}

Domingo-Calabuig, D. (2005). Indagaciones sobre una subjetividad cultivada. El problema del conocimiento en la teoría y práctica arquitectónica [Tesis doctoral no publicada]. Universitat Politècnica de València.

https://doi.org/10.4995/Thesis/10251/2682.

Finkel, D. (2008). Dar clase con la boca cerrada. Universitat de València.

Foqué, R. (2010). Building knowledge in architecture. University Press Antwerp.

Goldschmidt, G. (2014). Linkography: Unfolding the design process. The MIT Press.

Harrison, A. y Hulton, L. (2014). Design for the changing educational landscape: space, place and the future of learning. Routledge.

Harris, H. (2015). Radical pedagogies: architectural education and the British tradition. RIBA Publishing.

Huet, B. (1980). La Enseñanza de la arquitectura en Francia. 1968-1978. Arquitecturas Bis: Información Gráfica de Actualidad, 32-33, 1.

Lambert, G. (2014). La pédagogie de I'atelier dans l'enseignement de l'architecture en
France aux XIXème et XXème siècles, une approche culturelle et matérielle. Perspective, 1, 129-136.

https://perspective.revues.org/4412.

Linazasoro Rodríguez, J. I. (1984). Apuntes para una teoría del proyecto. Universidad de Valladolid.

Lizondo-Sevilla, L., Bosch-Roig, L., Ferrer-Ribera, C. y Alapont-Ramón, J.L. (2019). Teaching architectural design through creative practices. METU Journal of the Faculty of Architecture, 36(1), 41-60.

http://jfa.arch.metu.edu.tr/archive/0258-5316/ articles/metujfa2019108.pdf

Llorente Díaz, M. (2000). El saber de la arquitectura y de las artes. Universitat Politècnica de Catalunya.

Marina, J. A. (1993). Teoría de la inteligencia creadora. Editorial Anagrama.

Martín Rivas, M. (2016). Factores psicosociales de riesgo en el entorno académico. La carrera de arquitectura en la Universidad Politécnica de Madrid [tesis doctoral no publicada]. Universidad Complutense de Madrid. https://eprints.ucm.es/35832/

Ockman, J., Williamson, R. y Association of Collegiate Schools of Architecture. (2012). Architecture school: three Centuries of educating architects in North America. The MIT Press.

Parlamento Europeo y Consejo de la Unión Europea. (2005). Directiva 2005/36/CE relativa al reconocimiento de cualificaciones profesionales.

http://data.europa.eu/eli/dir/2005/36/oj

Riesco González, M. (2008). El enfoque por competencias en el EEES y sus implicaciones en la enseñanza y el aprendizaje. Tendencias Pedagógicas, 13, 79-106. https://revistas.uam.es/tendenciaspedagogicas/ article/view/1892

Thomas, J. W. (2000). A review of research on project- based learning. Autodesk Foundation.

Universitat Politècnica de València. (2025). Proyecto institucional de competencias transversales. Universitat Politécnica de València. https://www.upv.es/entidades/ICE/info/ Proyecto Institucional CT.pdf 
Vol.

NrO. 2 REVISTA DE ARQUITECTURA

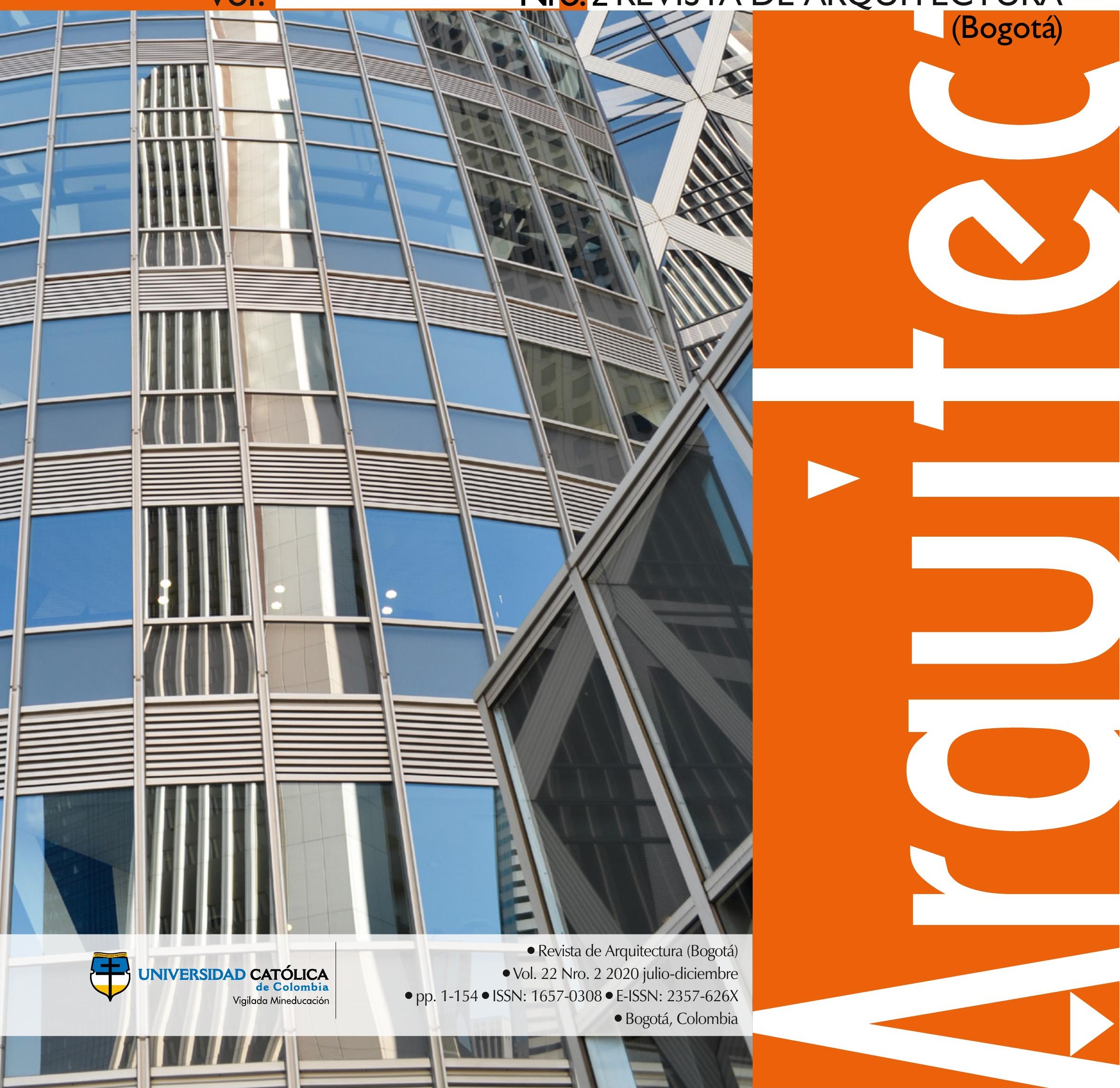


A Portada: Sokkuri (significa reflejo inverso) Mode Gakuen Cocoon Tower, Shinjuku, Tokyo, Japan Fotografía: Arquitecto José Tomás Pachajoa-Herrera (2012, diciembre)

\section{Enfoque y alcance}

La Revista de Arquitectura (Bogotá) ( (ISSN 1657-0308 Impresa y E-ISSN 2357-626X en línea) es una publicación científica seriada de acceso abierto, arbitrada mediante revisión por pares (doble ciego) e indexada, en donde se publican resultados de investigación originales e inéditos.

Está dirigida a la comunidad académica y profesional de las áreas afines a la disciplina. Es editada por la Facultad de Diseño y el Centro de Investigaciones (CIFAR) de la Universidad Católica de Colombia en Bogotá (Colombia).

La principal área científica a la que se adscribe la Revista de Arquitectura (Bogotá) según la OCDE es:

Gran área: 6. Humanidades

Área: 6.D. Arte

Disciplina: 6D07. Arquitectura y Urbanismo

También se publican artículos de las disciplinas como 2A02, Ingeniería arquitectónica; 5G03, Estudios urbanos (planificación y desarrollo); 6D07, Diseño.

Los objetivos de la Revista de Arquitectura (Bogotá) son:

- Promover la divulgación y difusión del conocimiento generado a nivel local, nacional e internacional

- Conformar un espacio para la construcción de comunidades académicas y la discusión en torno a las secciones definidas.

- Fomentar la diversidad institucional y geográfica de los autores que participan en la publicación.

- Potenciar la discusión de experiencias e intercambios científicos entre investigadores y profesionales.

- Contribuir a la visión integral de la arquitectura, por medio de la concurrencia y articulación de las secciones mediante la publicación de artículos de calidad.

- Publicar artículos originales e inéditos que han pasado por revisión de pares, para asegurar que se cumplen las normas éticas, de calidad, validez científica, editorial e investigativa.

- Fomentar la divulgación de las investigaciones y actividades desarrolladas en la Universidad Católica de Colombia
Palabras clave de la Revista de Arquitectura (Bogotá): arquitectura, diseño, educación arquitectónica, proyecto y construcción, urbanismo.

Idiomas de publicación: español, inglés, portugués y francés.

Título abreviado: Rev. Arquit.

Titulo corto: RevArq

\section{Políticas de sección}

La revista se estructura en tres secciones correspondientes a las líneas de investigación activas y aprobadas por la institución, y dos complementarias, que presentan dinámicas propias de la Facultad de Diseño y las publicaciones relacionadas con la disciplina.

Cultura y espacio urbano. En esta sección se publican los artículos que se refieren a fenómenos sociales en relación con el espacio urbano, atendiendo aspectos de la historia, el patrimonio cultural y físico, y la estructura formal de las ciudades y el territorio.

Proyecto arquitectónico y urbano. En esta sección se presentan artículos sobre el concepto de proyecto, entendido como elemento que define y orienta las condiciones proyectuales que devienen en los hechos arquitectónicos o urbanos, y la forma como estos se convierten en un proceso de investigación y nuevo de conocimiento. También se presentan proyectos que sean resultados de investigación, los cuales se validan por medio de la ejecución y transformación en obra construida del proceso investigativo. También se contempla la publicación de investigaciones relacionadas con la pedagogía y didáctica de la arquitectura, el urbanismo y el diseño.

Tecnología, medioambiente y sostenibilidad. En esta sección se presentan artículos acerca de sistemas estructurales, materiales y procesos constructivos, medioambiente y gestión, relacionados con los entornos social-cultural, ecológico y económico.

Desde la Facultad. En esta sección se publican artículos generados en la Facultad de Diseño, relacionados con las actividades de docencia, extensión, formación en investigación o internacionalización, las cuales son reflejo de la dinámica y de las actividades realizadas por docentes, estudiantes y egresados; esta sección no puede superar el $20 \%$ del contenido.

Textos. En esta sección se publican reseñas, traducciones y memorias de eventos relacionados con las publicaciones en Arquitectura y Urbanismo.
A Frecuencia de publicación

Desde 1999 y hasta el 2015, la Revista de Arquitectura (Bogotá) publicó un volumen al año, a partir del 2016 se publicarán dos números por año en periodo anticipado, enero-junio y julio-diciembre, pero también maneja la publicación anticipada en línea de los artículos aceptados (versión Post-print del autor).

La Revista de Arquitectura (Bogotá) se divulga mediante versiones digitales (PDF, HTML, EPUB, XML) e impresascon un tiraje de 700 ejemplares, los tiempos de producción de estas versiones dependerán de los cronogramas establecidos por la editorial.

Los tiempos de recepción-revisión-aceptación pueden tardar entre seis y doce meses dependiendo del flujo editorial de cada sección y del proceso de revisión y edición adelantado.

Con el usuario y contraseña asignados, los autores pueden ingresar a la plataforma de gestión editorial y verificar el estado de revisión, edición o publicación del artículo.
A Canje

La Revista de Arquitectura (Bogotá) está interesada en establecer canje con publicaciones académicas, profesionales o científicas del área de Arquitectura y Urbanismo, como medio de reconocimiento y discusión de la producción científica en el campo de acción de la publicación.

\section{Mecanismo}

Para establecer canje por favor descargar, diligenciar y enviar el formato: RevArq FP20 Canjes

Universidad Católica de Colombia (2020,
julio-diciembre). Revista de
Arquitectura (Bogotá), 22(2),
I-I52. Doi: 10.14718

ISSN: 1657-0308
E-ISSN: 2357-626X
Especificaciones:
Formato: 34 x $24 \mathrm{~cm}$
Papel: Mate II5 g
Tintas: Negro y policromía

Contacto

Dirección postal:

Avenida Caracas No. 46-72.

Universidad Católica de Colombia

Bogotá D.C.(Colombia)

Código postal: 111311

Facultad de Diseño

Centro de Investigaciones (CIFAR).

Sede El Claustro. Bloque "L", 4 piso

Diag. 46A No. $15 b-10$

Editor, Arq. César Eligio-Triana

Teléfonos:

+57 (1) $3277300-3277333$

Ext $3109 \cdot 311205146$

Fax: + 57 (1) 2858895
Correo electrónico:

revistadearquitectura@ucatolica.edu.co cifar@ucatolica.edu.co

Página WEB:

www.ucatolica.edu.co vínculo Revistas científicas

http://publicaciones.ucatolica.edu.co revistas-cientificas http://editorial.ucatolica.edu.co/ojsucatolica/revistas_ucatolica/index.php/RevArq 


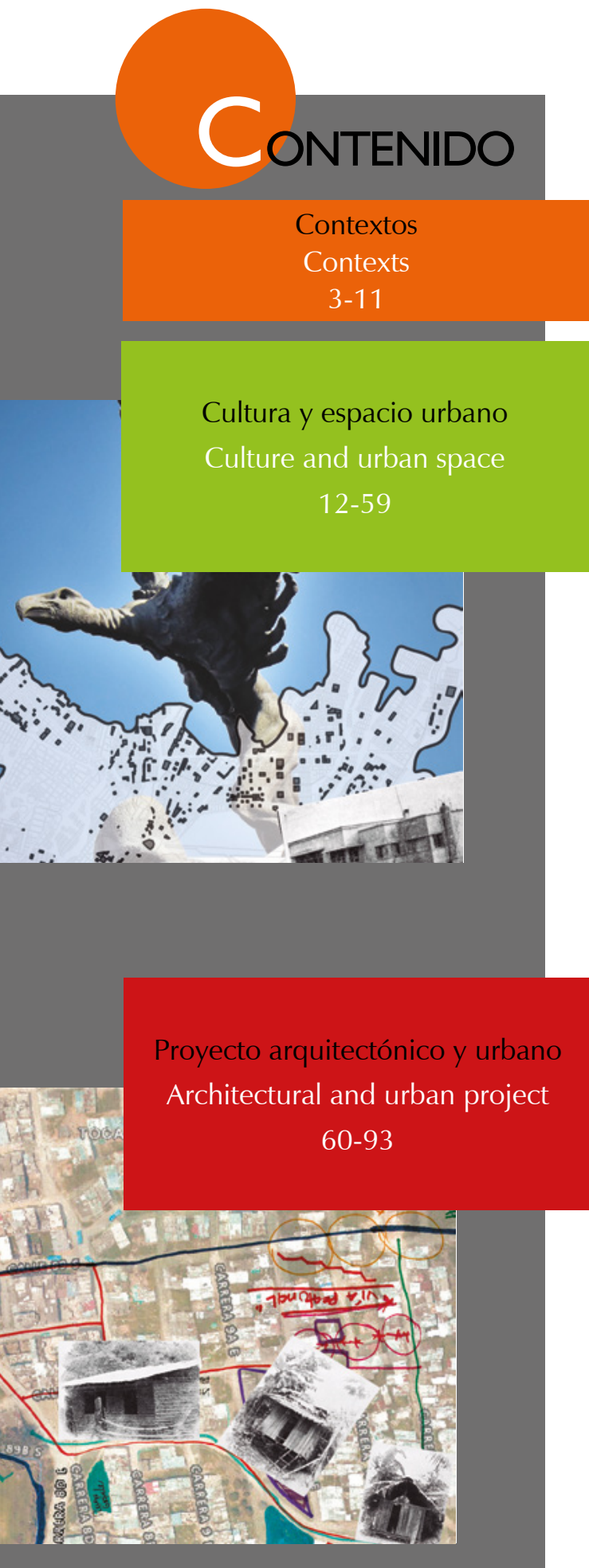

Tecnología, medioambiente y sostenibilidad

Technology, environment and sustainability 94-152

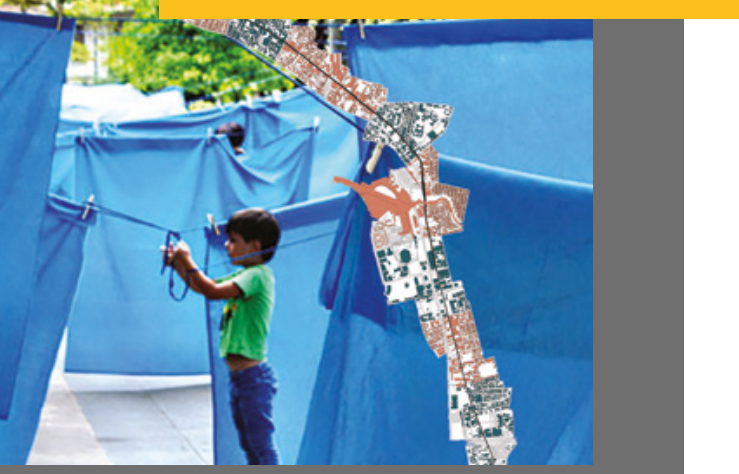

Espacio y tiempo del taller de proyectos arquitectónicos:

la Escuela de Arquitectura de Valencia

Débora Domingo-Calabuig

Laura Lizondo-Sevilla

La comunidad local en la valoración del patrimonio rural.

La escuela Francisco Arias en Lavalle

Isabel Durá-Gúrpide

Matías J. Esteves

ES Hábitat Accesible. Desarrollo de modelos conceptuales urbano-habitacionales.

Alina Delgado-Bohórquez

ES Monumentos y arte urbano: percepciones, actitudes y valores en la ciudad de Manizales.

Rodrigo Santofimio-Ortiz

Sandra Milena Pérez-Agudelo

ES Nueva centralidad en interfase urbano-rural (I-UR)

Caso: sector Umapalca, zona sur de Arequipa Metropolitana

David Jesús Lovon-Caso

Ana de los Ángeles Larota-Sanz

ES Arquitecturas tradicionales y populares: un reto para la historiografía de la arquitectura en Colombia

Guillermo Gutiérrez-Morales

Mito o realidad.

Gustave Eiffel y el templo San Marcos de Arica

Darci Gutiérrez-Pinto

ES La caminabilidad como estrategia proyectual para

las redes peatonales del borde urbano.

Barrio Sierra Morena, Usme.

Marielena Medina-Ruiz

Siudades costeras e indicadores de sostenibilidad:

una aproximación desde el metabolismo urbano de la calle

El caso de la avenida Juan Ponce de León, en San Juan, Puerto Rico

María Helena Luengo-Duque

Fabricación de ladrillos con polvo-residuo de mármol en México. 106

Propiedades físicas y mecánicas del polvo-residuo de mármol

de la provincia de la Comarca Lagunera, en México

C. Ponce-Palafox
Julián Carrillo
A. López-Montelongo

Determinación de emisiones de Gases de Efecto Invernadero (GEI) en una matriz energética sustentable mediante análisis de escenarios.

Estudio de caso en zonas áridas con alto riesgo hídrico

Alba Inés Ramos Sanz

ES La participación infantil en proyectos urbanos.

El juego en espacios públicos para la promoción del aprendizaje

de conceptos ambientales

Carolina Polo-Garzón

Adriana Patricia López-Valencia

Alba Inés Ramos Sanz

ES Gestión territorial y sus implicaciones con el ODS11

Reflexiones desde Colombia y Costa Rica

Tania Giraldo-Ospina

Félix Zumbado-Morales 
Espacio y tiempo del taller de proyectos arquitectónicos:

la Escuela de Arquitectura de Valencia

ن Space and time of the design studio: the Architectu

La comunidad local en la valoración del patrimonio rural. La  escuela Francisco Arias en Lavalle

ن The local community in the appreciation of rural heritage. Francisco Arias ¿ school in Lavalle

Hábitat accesible. Desarrollo de modelos conceptuales

ij Affordable Habitat - The Development of Housing and Neighbourhood

Simulation Models

Monumentos y arte urbano: percepciones, actitudes y valores en la ciudad de Manizales

m ن Manizales $\stackrel{\infty}{+}$ Umapalca, zona sur de Arequipa Metropolitana

New Centrality in Rural Urban Interface. Case: Sector Umapalca, South Zone of Metropolitan Arequip

0

Arquitecturas tradicionales y populares: un reto para la

historiografía de la arquitectura en Colombia

ن Traditional and popular architectures: a challenge for architecture

这

¿ேं

\section{Ciudades costeras e indicadores de sostenibilidad:}

よ

caso de la avenida Juan Ponce de León, en San Juan, Puerto Rico

Coastal cities and sustainability indicators: an approach from the urban

metabolism of the street. The case of Juan Ponce de León avenue, in San Juan, Puerto Rico

Fabricación de ladrillos con polvo-residuo de mármol en México. - Propiedades físicas y mecánicas del polvo-residuo de mármol de 으 la provincia de la Comarca Lagunera, en México

ن Physical and mechanical properties of bricks with dust residue from marble in

México.Physical and mechanical properties of the marble dust-residue from the Comarca Lagunera Province, in Mexico

\section{Julián Carrillo}

Determinación de emisiones de Gases de Efecto Invernadero * (GEI) en una matriz energética sustentable mediante análisis de

- escenarios. Estudio de caso en zonas áridas con alto riesgo hídrico ن Determination of greenhouse gas emissions (GHG) in a sustainable energy matrix $\varangle \quad$ through scenario analysis. Case Study in arid zones with high hydric risk

\section{La participación infantil en proyectos urbanos. El juego en}

ㄴ espacios púb

$\stackrel{2}{\sim}$ ambientales

ن Children's participation in urban projects. Play in public spaces for the

$\varangle$ promotion of the learning of environmental concepts Gestión territorial y sus implicac
desde Colombia y Costa Rica

₹ desde Colombia y Costa Rica

Land Management and its implications with SDG II Reflections from

ن Colombia and Costa Rica

¿ Tania Giraldo-Ospina
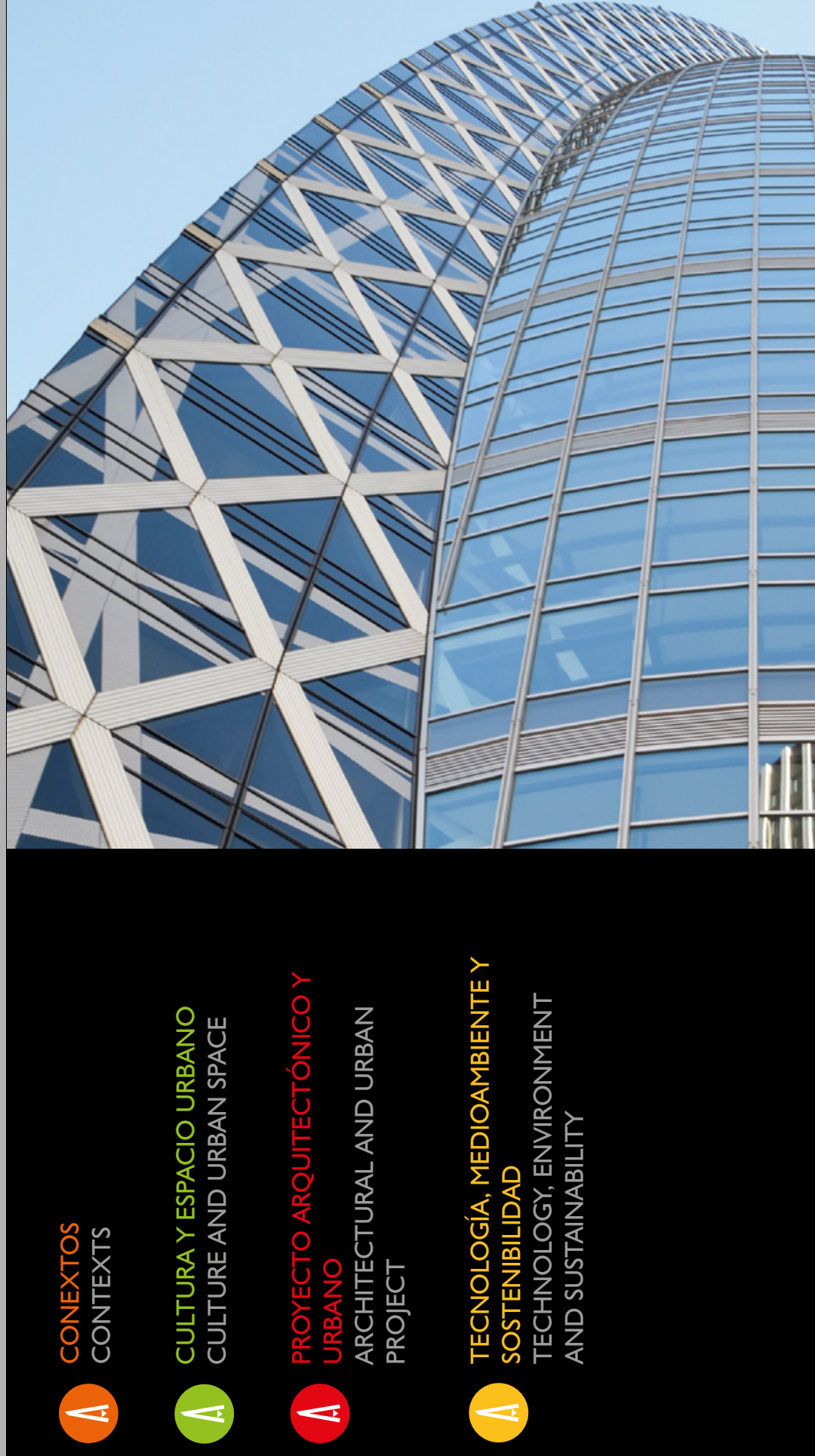

La Revista de Arquitectura es de acceso abierto, arbitrada e indexada y está presente en:

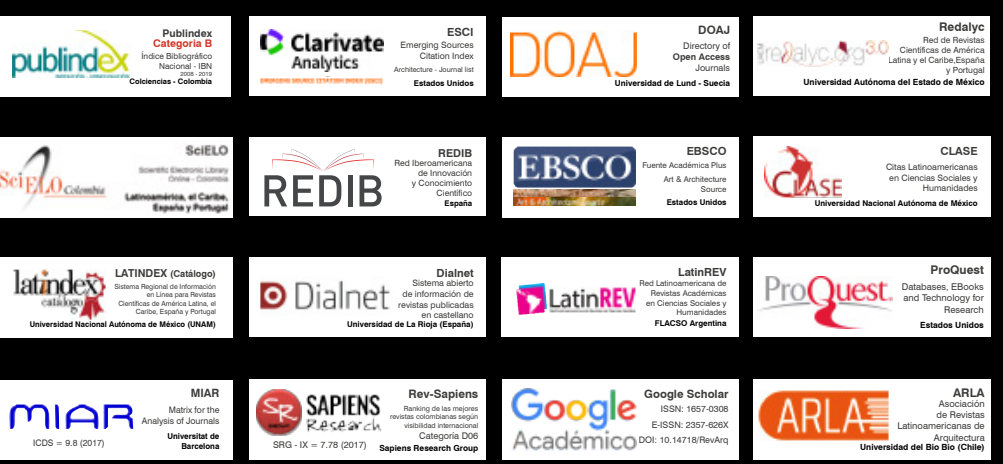

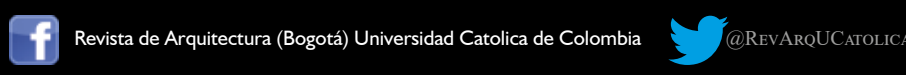

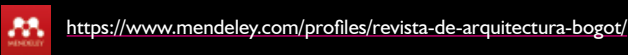

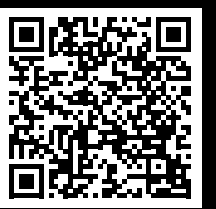

† UNIVERSIDAD CATÓLICA

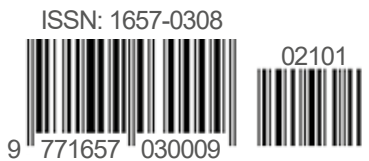

